\title{
Medical student perspectives on integrated teaching within medical school
}

This article was published in the following Dove Press journal:

Advances in Medical Education and Practice

\section{Ahmad Salha \\ Amir-Seena Saberi-Movahed Syed Waqar}

Faculty of Medicine, St George's Hospital Medical School, London, UK
Correspondence: Ahmad Salha

Faculty of Medicine, St George's Hospital Medical School, Cranmer Terrace,

London SWI7 ORE, UK

Tel +44 7779555525

Email ahmad_salha@hotmail.co.uk

\section{Dear editor}

We read the article by Atta and AlQahtani ${ }^{1}$ with great interest and wish to contribute a medical student perspective. We understand the study's main findings to be improved test scores and student satisfaction as a result of integrated pathology and radiology teaching. Our medical school implements a successful integrated spiral curriculum which is popular among students, so we were intrigued by the prospect of integration in these two essential areas of medical education.

Another study by Eisenstein et $\mathrm{al}^{2}$ also involved integrating pathology and radiology among other fields. Similarly, this study improved student satisfaction in a curriculum while achieving other important goals of integration, such as allowing a more patientcentered approach to learning and student input into educational reform. From our experiences, our medical teaching does not heavily integrate radiology and pathology; however, combined knowledge from both areas is commonly expected within examinations. It seems logical that integration would put less pressure on a student's ability to understand and assimilate knowledge of these areas; in a manner required in assessments and clinical practice. This could partly explain the improved outcomes and satisfaction in the study musculoskeletal (MSK) module within the original article. ${ }^{1}$

While the positive results in your study ${ }^{1}$ are encouraging and provide significant evidence, there are several intricacies that should be considered further before permanently implementing an integrated curriculum of this manner into MSK and other topics of the medical curriculum. As explored by Kanter, ${ }^{3}$ development or revision of a medical curriculum is not a simple task; this process necessitates in depth planning of course structure, logistics, learning objectives, and assessment. It is because of this that we are wary on a recommendation of module-wide integration based solely on the results of this study. Additionally, integrated pathology and radiology may lend itself more to some modules than others; it must be carefully assessed for which modules integration would be beneficial. Furthermore, Willis ${ }^{4}$ suggested implementation of integrated teaching should be small and manageable; therefore, perhaps it would be best to try this style of integration in modules individually, before recommending large-scale changes.

An aspect not explored by this study ${ }^{1}$ is a comparison of student performance and satisfaction in MSK and gastrointestinal (GIT) modules prior to an integrated system. A difference in examination outcomes and student satisfaction between both modules 
may exist regardless of the introduced integration. It could simply be a matter that students find MSK-related radiology and pathology easier compared to their GIT counterparts. It would be interesting to explore examination performance further. Both by comparing results of the MSK and GIT modules with previous level $\mathrm{V}$ cohorts, and the assessments in these two modules, of the study cohort, in their previous years of study.

We appreciate the need to keep medical education continually evolving alongside the medical field itself. Integration of areas as described in this study ${ }^{1}$ may be a powerful tool to incorporate in medical curricula. However, further evidence-based exploration is needed before this or similar integration approaches are implemented across-the-board.

\section{Disclosure}

The authors report no conflicts of interest in this communication.

\section{References}

1. Atta I, Al Qahtani F. Integrated pathology and radiology learning for a musculoskeletal system module: an example of interdisciplinary integrated form. Adv Med Educ Pract. 2018;9:527-533.

2. Eisenstein A, Vaisman L, Johnston-Cox H, et al. Integration of basic science and clinical medicine: the innovative approach of the cadaver biopsy project at the Boston University School of Medicine. Academic medicine : journal of the Association of American Medical Colleges. 2014;89(1):50-53.

3. Kanter SL. Toward better descriptions of innovations. Acad Med. 2008;83(8): 703-704.

4. Willis S. Refocusing the curriculum: making interdisciplinary efforts work. Assoc for Supervision Curriculum Dev Update. 1995;37:1. 


\section{Authors' reply}

Ihab Shafek Atta'

Fahd Nasser AIQahtani²

'Department of Pathology, Faculty of Medicine, Al-Azhar University (Assuit Branch), Cairo, Egypt; ${ }^{2}$ Department of Radiology, Faculty of Medicine, Albaha University, Al-Aqiq, Saudi Arabia

Correspondence: Ihab Shafek Atta

Department of Pathology, Faculty of Medicine, Al-Azhar University (Assuit Branch), Cairo, Egypt

Email Ihab.bassyouny@azhar.edu.eg

\section{Dear editor}

Our study ${ }^{1}$ was focused on the integration of pathology and radiology learning in the musculoskeletal (MSK) module as an interdisciplinary form of integration. Our study is unique as no previous studies handled this mode of pathology/radiology integration at the level of undergraduate education, especially in the basic years. Some authors described the integration of pathology and radiology in breast cancer at the level of postgraduate education, ${ }^{2}$ while others described integration of both disciplines at the postgraduate and residency levels to enhance the reporting in an attempt to improve the overall quality of patient care. ${ }^{3}$

The study of Eisenstein et $\mathrm{al}^{4}$ in which the authors described the Cadaver Biopsy Project is a sustainable model of vertical integration in which faculty and select senior medical students obtained biopsies of cadavers during the first-year gross anatomy course (fall 2009) and used these to develop clinical cases for courses in histology (spring 2010), pathology (fall 2010-spring 2011), and radiology (fall 2011 or spring 2012). As you noted from date mentioned in Eisenstein et al's ${ }^{4}$ study, it was implemented as individual disciplines through a vertical manner and not across the interdisciplinary form which more disciplines learned in an integral way within the allocated time. So, this study is far different from our study in various aspects. Also, our examinations of all modules are in an integrated form in which many questions for different disciplines are addressed by short case scenarios, but this does not explain the improved outcomes in the MSK module, as this integrated model of examination is globalized across all the other modules, and the student performance and satisfaction are relatively higher and restricted to the MSK module.

We agree that the development or revision of a medical curriculum is not a simple task, but it is mandatory in some circumstances to do periodic partial curricular reforms according to the outcomes, student performance, and external threats. As our school adopted a fully integrated-based system since 7 years, some minor curricular reforms have to be done according to inferences and feedback obtained. As a result of our previous study, ${ }^{5}$ we found the low student performance to be coming from radiology, so in an attempt to correct this we selected the module in which the weight of radiology is high; hence, MSK was selected to enhance the radiology student performance, and we also chose this since this is one area where the implementation of pathology/radiology integration model is more beneficial for both disciplines. All learning goals and objectives were investigated and revised by experts. The educational resources and logistic material were well prepared.

The current study was carried out on level V students who studied the gastrointestinal (GIT) and MSK in a vertical manner; so, the students who studied the GIT module were the same ones who studied the MSK. So, we undertook a comparison between the same students for the two consecutive modules under the same circumstances. The comparison was between GIT module an example of low level of integration with MSK module; an example of high level of integration "interdisciplinary form" vertical comparison with the module counterpart of the previous year prior to the interdisciplinary integration form means comparison with different students with different variables which are of limited value in current study but it seems of great value in evaluating the whole curriculum. Instead, we will reassess the experience in the upcoming students of the Phase V for more confirmation before transferring the experience into the next modules of the same level; so, we will not globalize the changes for all modules at the same time, but in a serial and step-by-step manner.

\section{Disclosure}

The authors report no conflicts of interest in this communication.

\section{References}

1. Atta IS, Alqahtani FN. Integrated pathology and radiology learning for a musculoskeletal system module: an example of interdisciplinary integrated form. Adv Med Educ Pract. 2018;9:527-533.

2. Tawfik O, Redick ML. Integrated Radiology/Pathology Service for Breast Cancer. Critical Values. 2009;2(3):23-26.

3. Sorace J, Aberle DR, Elimam D, Lawvere S, Tawfik O, Wallace WD. Integrating pathology and radiology disciplines: an emerging opportunity? BMC Med. 2012;10:100.

4. Eisenstein A, Vaisman L, Johnston-Cox H, et al. Integration of basic science and clinical medicine: the innovative approach of the cadaver biopsy project at the Boston University School of Medicine. Acad Med. 2014;89(1):50-53.

5. Atta IS, Alqahtani FN. Matching medical student achievement to learning objectives and outcomes: a paradigm shift for an implemented teaching module. Adv Med Educ Pract. 2018;9:227-233. 
Dove Medical Press encourages responsible, free and frank academic debate. The content of the Advances in Medical Education and Practice 'letters to the editor' section does not necessarily represent the views of Dove Medical Press, its officers, agents, employees, related entities or the Advances in Medical Education and Practice editors. While all reasonable steps have been taken to confirm the content of each letter, Dove Medical Press accepts no liability in respect of the content of any letter, nor is it responsible for the content and accuracy of any letter to the editor.

Advances in Medical Education and Practice

Dovepress

\section{Publish your work in this journal}

Advances in Medical Education and Practice is an international, peerreviewed, open access journal that aims to present and publish research on Medical Education covering medical, dental, nursing and allied health care professional education. The journal covers undergraduate education, postgraduate training and continuing medical education including emerging trends and innovative models linking education, research, and health care services. The manuscript management system is completely online and includes a very quick and fair peer-review system. Visit http://www.dovepress.com/testimonials.php to read real quotes from published authors.

Submit your manuscript here: http://www.dovepress.com/advances-in-medical-education-and-practice-journal 